\section{Stuck in the mud}

\section{The Environmental Protection Agency must gather data on the toxicity of spreading sewage sludge.}

S ome 30 years ago, as the United States began to tighten its environmental regulations on residential and industrial wastewater, operators of sewage-treatment plants embraced what seemed an eminently sensible idea. They decided to take the rich organic sludge left over after clean water is extracted and sell it to farmers as fertilizer.

The practice proved popular, and has become increasingly common internationally. Today, some $60 \%$ of sludges, innocuously dubbed 'biosolids' by the US Environmental Protection Agency (EPA), are used as fertilizer in the United States.

The programme might well be as sensible as it seems. It is possible that the millions of tonnes of sludge being spread across the rural landscape contain no significant levels of toxic chemicals, heavy metals or disease-causing organisms. It may all be perfectly benign. The disturbing fact is that no one knows.

In what can only be called an institutional failure spanning more than three decades - and presidential administrations of both parties - there has been no systematic monitoring programme to test what is in the sludge. Nor has there been much analysis of the potential health effects among local residents - even though anecdotal evidence suggests ample cause for concern.

In fact, one of the studies used to refute potential dangers, published in the Journal of Environmental Quality in 2003 by researchers at the University of Georgia in Athens, has been called into question (see page 262). Even the National Academy of Sciences seems to have been taken in. A 2002 report from the academy cited the then unpublished Georgia work as evidence that the EPA had investigated and dismissed claims that sewage sludge had killed cattle, but the study had not looked at the dairy farms in question. And although it may be technically true that there was no documented evidence of sludge applications causing human illness or death, the academy also cited work by an EPA whistleblower, David Lewis, suggesting at least an association between these factors. If anything, recent research underscores those findings.

The Georgia citation notwithstanding, the academy did outline a sound plan for moving forward. It recommended among other things that the EPA improve its risk-analysis techniques; survey the sludges for potential contaminants; begin tracking health complaints; and conduct some epidemiological analyses to determine whether these reports merit concern.

The EPA has completed none of those tasks. Six years later, the agency is only now trying to finish its evaluation of potential contaminants and has yet to establish a system for monitoring reports of health problems. Agency officials say that they are working on risk-analysis tools, but have yet to undertake any kind of epidemiological studies.

The EPA certainly has other competing priorities, and the fault here does not lie only with the current administration or any single researcher. Regardless, these safety questions deserve answers, and the EPA should be able to deliver them. It is time to get the data.

\section{Negative results}

\section{Retracted papers require a thorough explanation of what went wrong in the experiments.}

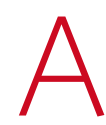

t first glance it seems to be a shining example of the scientific method in action. Two papers published by biochemist Homme Hellinga and his students at Duke University Medical Center in Durham, North Carolina, claimed a breakthrough in rational enzyme design. Last year, another chemist found that Hellinga's enzymes didn't actually work, which led to the retraction of the two papers this February (see page 275). Then, this March, a third group published research showing that rational enzyme design really is possible. All has ended happily, it seems, with the field marching forward in triumph.

But examined more closely, the episode reveals some less than happy aspects of science as it is actually practised. For example, the problems with Hellinga's enzymes were identified by John Richard at the State University of New York in Buffalo, who hoped to use the proteins in his own work. In effect, Richard and his two co-workers wasted seven months and tens of thousands of dollars failing to reproduce the results from Hellinga's lab. Richard's subsequent efforts to correct the scientific record thus came at considerable cost, with no discernable benefit to his own career.
This is a perennial problem in science. Many researchers who come across non-reproducible work save themselves extra hassle and money by simply not pursuing it further. Meanwhile, those who refuse to let it go - like Richard - gain nothing.

The process has been even more difficult for Hellinga's former student, Mary Dwyer. Hellinga accused Dwyer of faking data in the now-retracted papers, although he apparently had no evidence of intentional wrongdoing on her part. A Duke inquiry later cleared Dwyer of any misconduct, but her mentor's accusations could be more damaging to her career than the retractions.

The situation highlights the vulnerability of students in the system of scientific mentorship. Indeed, Hellinga's decision to accuse Dwyer was questionable. As Dwyer's adviser, Hellinga was responsible for training her. If she made mistakes, they are ultimately his responsibility. Instead, by accusing her, he cut off any possibility of frank and open discussion.

In the end, despite Richard's work, a misconduct inquiry and two retractions, the scientific community still does not know what went wrong, and may never know. This is perhaps most damaging to Hellinga, as the scientific community is now unsure whether to trust his prior and subsequent work. He and Duke owe the world a more thorough explanation of his conduct, and of his scientific work in question. Until then, this episode will continue to be a cautionary tale about the weaknesses - not the strengths - of the scientific process. 